\title{
Fluoride release from fluoride varnish under in vitro and in vivo conditions
}

\section{Uwalnianie fluorków z lakierów fluorowych w warunkach in vitro i in vivo}

\author{
Dagmara Piesiak-Pańczyszyn ${ }^{B}$, Urszula Kaczmarek ${ }^{A,-}-\mathrm{F}$ \\ Department of Conservative Dentistry and Pedodontics, Wroclaw Medical University, Poland \\ A - research concept and design; $\mathrm{B}$ - collection and/or assembly of data; $\mathrm{C}$ - data analysis and interpretation; \\ $D$ - writing the article; $E$ - critical revision of the article; $F$ - final approval of the article
}

\section{Address for correspondence \\ Urszula Kaczmarek}

E-mail: urszula.kaczmarek@umed.wroc.pl

Funding sources

None declared

Conflict of interest

None declared

Received on September 12, 2017

Reviewed on October 15, 2017

Accepted on October 21, 2017
DOI

10.17219/dmp/78887

Copyright

○ 2017 by Wroclaw Medical University

and Polish Dental Society

This is an article distributed under the terms of the

Creative Commons Attribution Non-Commercial License

(http://creativecommons.org/licenses/by-nc-nd/4.0/)

\begin{abstract}
Background. Fluoride varnishes are commonly used in the prevention of caries.

Objectives. To compare the newly introduced plates for mandibular condyle neck fracture treatment.

Material and methods. The measured amounts of Colgate ${ }^{\oplus}$ Duraphat ${ }^{\oplus} 50 \mathrm{mg} / \mathrm{mL}$ Varnish Dental Suspension containing sodium fluoride $5 \%$ (22.600 ppm F) were applied on the teeth of 10 subjects and onto 30 specimens prepared from extracted human teeth. Levels of fluoride release in vivo study were assessed in unstimulated saliva at the baseline and after 1,2 and $168 \mathrm{~h}$ from the application, and in vitro study after $1,2,24,48$ and $168 \mathrm{~h}$ from the baseline with the use of ion specific electrode. The specimens were immersed into artificial saliva with pH adjusted to 4,5 and 7, 10 specimens per each medium, and stored in room temperature.
\end{abstract}

Results. Under in vivo conditions, after $1 \mathrm{~h}$ following the application, the fluoride level increased 16-fold. After $2 \mathrm{~h}$ it slightly dropped to 15 -fold higher, and after $168 \mathrm{~h}$ to 5 -fold higher from the baseline $(0.55 \pm 0.49 \mathrm{ppm})$. Under in vitro conditions, the cumulative fluoride release within $168 \mathrm{~h}$ was the highest to the medium with pH 4 (9.95 ppm), slight lower with pH 5 (9.39 ppm) and substantially lower with pH7 (5.72 ppm). Regression analysis showed that fluoride release into artificial saliva was associated with time and pH; however, the acidity of the medium showed the higher impact than the time of release.

Conclusions. The varnish released the maximum amount of fluoride to saliva within the first hours after application and the levels decreased at each period thereafter. Under in vivo conditions, a single application of the varnish maintained the salivary fluoride levels above the baseline up to $168 \mathrm{~h}$, whereas under in vitro conditions the release of fluoride from the varnish was related to the acidity of the immersion medium.

Key words: fluoride release, fluoride varnish

Słowa kluczowe: uwalnianie fluorków, lakiery fluorowe 
Currently, more than 30 fluoride varnishes are available on the market, varying in composition and delivery system and in the content of fluoride, which is either $2.26 \%$, $0.77 \%$ or $0.1 \%{ }^{1,2}$ Some of them, apart from $5 \%$ sodium fluoride, can contain additional potentially active chemical compounds (e.g. casein phosphopeptide-amorphous calcium phosphate - ACP-CPP, calcium sodium phosphosilicate - CSPS, tricalcium phosphate - TCP).

Fluoride varnish is a convenient form for topical fluoride application providing prolonged contact of fluoride with the dental surface. The first varnish, marketed in the 1960 s, was Duraphat ${ }^{\circledR}$ containing 5\% sodium fluoride (2.25\%, i.e. 22,600 ppm F) in ethanol-resin (colophonium) system and its yellowish color facilitates the control of application. The second fluoride varnish, introduced in the 1970s, was silane fluoride varnish Fluor Protector ${ }^{\circledR}$ containing 1000 ppm F. ${ }^{3}$ Duraphat has been the most commonly used fluoride varnish and has been subjected to many in vivo and in vitro studies. ${ }^{3-9}$ It is indicated for both caries control and dentin hypersensitivity. ${ }^{5,10}$

The Cochrane reviews on the use of fluoride therapies in caries prevention concluded that fluoride varnishes applied 2-4 times a year substantially reduces carious lesions in children by $37 \%$ in primary dentition and by $43 \%$ in permanent dentition. ${ }^{5}$ The expert panel of the American Dental Association (ADA), based on a meta-analysis of numerous studies, confirmed with moderate certainty the benefit of $2.26 \%$ fluoride varnish applied at least twice per year for caries prevention in the primary teeth among children aged 6 months to 8 years and for caries prevention in permanent teeth among children aged 5 to 15 years, but with low certainty for root caries prevention in adults. ${ }^{1,11}$

The aim of the study was to assess fluoride release under in vivo and in vitro conditions after a single application of Colgate Duraphat Varnish 50 mg/mL Dental Suspension.

\section{Material and methods}

Fluoride varnish Colgate Duraphat Varnish $50 \mathrm{mg} /$ $\mathrm{mL}$ Dental Suspension containing $1 \mathrm{~mL} 50 \mathrm{mg}$ of sodium fluoride equivalent to $22.6 \mathrm{mg}$ of fluoride was used to assess fluoride release under in vivo and in vitro conditions. The other ingredients of this product are ethanol 96\%, white wax, shellac, colophony, mastic, saccharin, and raspberry essence. ${ }^{12}$ Ten young adult volunteers were involved in the in vivo study. They fulfilled the following criteria: age over 18, at least 24 natural teeth, no unfilled carious decays, no prosthetic appliances, orthodontic appliances, gingivitis or periodontitis and mucositis as well as no asthma or allergies, and no reported professionally applied fluoride specimens in the period of the last 6 months. Fluoride varnish was applied on dried labial/buccal and occlusal dental surfaces. The subjects were asked to refrain from food and beverages consumption for at least $1 \mathrm{~h}$ after the procedure. Before and after application of the measured amount of flu- oride varnish, samples of unstimulated mixed saliva were collected from the subjects at time point 0 (the baseline), and 1, 2 and $168 \mathrm{~h}$ later. In centrifuged salivary samples, fluoride levels (expressed in ppm) were assessed with the use of ionic selective electrode (Orion ${ }^{\circledR}$ 9609). Material for the in vitro study comprised 15 extracted human third molars, obtained with the patient's permission, with sound enamel, free of carious lesions, demineralization and enamel defects, which were stored in thymolized saline until use. Two $5 \times 5 \mathrm{~mm}$ sections were cut from each tooth. There were 3 groups with 10 specimens; each consisted of 5 buccal and 5 lingual enamel surfaces. Samples were rinsed and cleaned to remove debris, and then dried. Red nail lacquer was applied to all dentine surfaces leaving the enamel surface exposed. The amount of fluoride varnish painted on each specimen was measured by weighing the specimen with the use of an analytical balance before and after the application of, on the average, $0.01(0.003) \mathrm{mL}$, i.e. $0.226 \mathrm{mg}$ of fluoride. The painted specimens were immersed into $5 \mathrm{~mL}$ of artificial saliva with $\mathrm{pH}$ adjusted to $\mathrm{pH} 4,5$ and 7 , with 10 specimens per each medium at a different $\mathrm{pH}$, and stored in room temperature with agitation. Artificial saliva consisted of $\mathrm{NaCl}(0.4 \mathrm{~g}), \mathrm{KCl}(4.0 \mathrm{~g})$, urea ( $1 \mathrm{~g}), \mathrm{Na}_{2} \mathrm{~S} \cdot 9 \mathrm{H}_{2} \mathrm{O}$ (0.005 g), $\mathrm{NaH}_{2} \mathrm{PO}_{4} \cdot 2 \mathrm{H}_{2} \mathrm{O}$ and $\mathrm{CaCl}_{2} \cdot 2 \mathrm{H}_{2} \mathrm{O}$, and $1 \mathrm{M} \mathrm{NaOH}$ or $1 \mathrm{M} \mathrm{HCl}$ to adjust $\mathrm{pH}$ to $4.0,5.0$ or 7.0 . At the determined testing intervals (i.e. after 1, 2, 24, 48 and $168 \mathrm{~h}$ from the baseline), the specimens were transferred to $5 \mathrm{~mL}$ of fresh artificial saliva in new vials. The fluoride levels in the left media were assessed with the use of an ionic selective electrode. The cumulative release of fluoride ions and their emission between the measurements at each of the time points was expressed as ppm.

The study protocol was approved by the Bioethics Committee of the Wroclaw Medical University (KB 45/2016).

\section{Statistical analysis}

The obtained data was analyzed for normality and equality of variance, and the means were compared using a one-way ANOVA with Tukey's post hoc test using Statistica 12.0 software. The null hypothesis, verified by multiple regression analysis, posited that there would be significant differences in fluoride ions release associated with the time from application, amount of varnish used, salivary fluoride level at baseline, and $\mathrm{pH}$ of artificial saliva. For all statistical tests, the significance level was set at $\mathrm{p}<0.05$.

\section{Results}

\section{In vivo study}

In the clinical study, the mean amount of the applied varnish was $0.17(0.05) \mathrm{mL}$, i.e. 3.86 (1.06) $\mathrm{mg}$ of fluoride. Salivary fluoride level at the baseline was $0.11(0.04) \mathrm{ppm}$, 


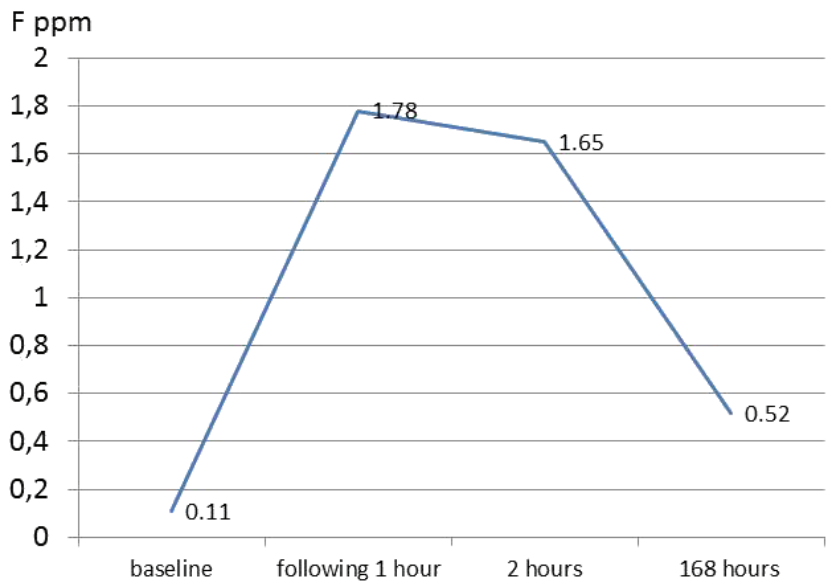

Fig. 1. Fluoride concentration in saliva before and after the varnish application (in vivo study)

ranging from 0.06 to $0.18 \mathrm{ppm}$. After $1 \mathrm{~h}$ following the fluoride varnish treatment, the concentration increased ca. 16-fold, and was 1.78 (0.63) ppm. After the next hour ( $2 \mathrm{~h}$ following the application), it dropped slightly to 15 -fold higher $(1.65$ (1.01) ppm) and after $168 \mathrm{~h}$ from the baseline to 5 -fold higher $(0.55$ (0.49) ppm) (Fig. 1).

Data of the regression analysis (Table 1 ) showed that none of the calculated regression coefficients for the analyzed variables was statistically significant ( $p>0.05$ ); therefore, it was not possible to construct a prediction model of fluoride release to saliva. Admittedly, the rate of reduction of salivary fluoride release following the use of varnish was rather high. The regression coefficient b was 0.0039 ppm per hour, but it was not statistically significant $(\mathrm{p}=0.063>0.05)$.

\section{In vitro study}

In the in vitro study, the mean amount of applied varnish was $0.010(0.003) \mathrm{mL}$, i.e. $0.226(0.067) \mathrm{mg}$ of fluoride, and did not differ significantly between groups.

Table 1. Results of multiple regression analysis for in vivo study

\begin{tabular}{|l|c|c|c|}
\hline \multirow{2}{*}{ Effect } & \multicolumn{3}{|c|}{$\mathrm{F}(\mathrm{ppm})$} \\
\cline { 2 - 4 } & $\mathrm{b}$ & $\mathrm{SE}_{\mathrm{b}}$ & $\mathrm{p}$-value \\
\hline Free term & 0.055 & 0.889 & 0.951 \\
F0 (ppm) & 4.974 & 3.977 & 0.219 \\
Fa (ppm) & 0.143 & 0.155 & 0.362 \\
t (hour) & -0.004 & 0.002 & 0.063 \\
\hline
\end{tabular}

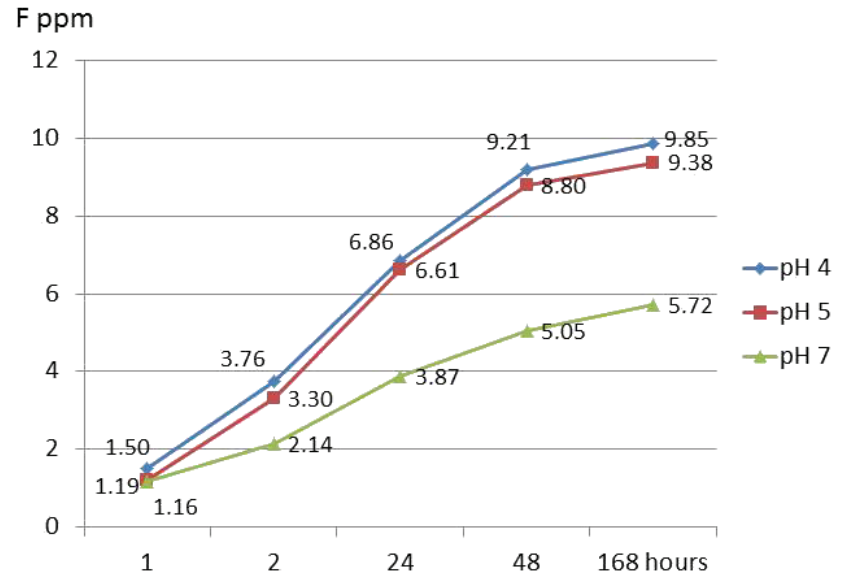

Fig. 2. Cumulative fluoride release (in vitro study)

Cumulative fluoride release showed that the lowest ions emission was to the artificial saliva with $\mathrm{pH} 7$ and only slightly lower at pH 5 compared to the medium with $\mathrm{pH} 4$ (Fig. 2).

Fluoride release between the measurement time points is seen in Table 2. Greater ion emission was observed between 1 and $2 \mathrm{~h}$ than within $1 \mathrm{~h}$ from the time the samples were placed into artificial saliva with $\mathrm{pH} 4$ and 5 , contrary to the medium with $\mathrm{pH} 7$, where the utmost increase was noticed after $1 \mathrm{~h}$.

Data of regression analysis showed that the reduction of fluoride release to the artificial saliva was associated with time and $\mathrm{pH}$. The acidity of the medium presented the higher impact than the time of release (Table 3).

\section{Discussion}

The integrity of the tooth hard tissues is associated with the saturation of the surrounding oral fluids with calcium and phosphate ions in relation to the dental

Table 3. Results of multiple regression analysis for in vitro study

\begin{tabular}{|l|c|c|c|}
\multirow{2}{*}{ Effect } & \multicolumn{3}{|c|}{$\mathrm{F}(\mathrm{ppm})$} \\
\cline { 2 - 4 } & $\mathrm{b}$ & $\mathrm{SE}_{\mathrm{b}}$ & $\mathrm{p}$-value \\
\hline Free term & 3.542 & 0.318 & $<0.001$ \\
$\mathrm{pH}$ & -0.288 & 0.057 & $<0.001$ \\
$\mathrm{t}$ (hours) & -0.007 & 0.001 & $<0.001$ \\
\hline
\end{tabular}

$\mathrm{F}=3.54-0.0071 \times \mathrm{t}-0.288 \times \mathrm{pH}$.

Table 2. Mean values of fluoride release (ppm) in vitro for the time periods between

\begin{tabular}{|c|c|c|c|c|c|}
\hline Time point & 1 hour & 1 and $2 \mathrm{~h}$ & 2 and $24 h$ & 24 and $48 \mathrm{~h}$ & 48 and $168 h$ \\
\hline Artificial saliva & $x(S D)$ & $x(S D)$ & $x(S D)$ & $x(S D)$ & $x(S D)$ \\
\hline $\mathrm{pH} 4$ & $1.49(0.35)$ & $2.26(0.95)$ & $3.10(0.33)$ & $2.35(0.37)$ & $0.63(0.16)$ \\
\hline $\mathrm{pH} 5$ & $1.19(0.30)$ & $2.11(0.61)$ & $3.31(1.03)$ & 2.19 (1.04) & $0.58(0.17)$ \\
\hline $\mathrm{pH} 7$ & $1.16(0.52)$ & $0.98(0.78)$ & $1.73(1.06)$ & $1.18(0.30)$ & $0.67(0.17)$ \\
\hline
\end{tabular}


mineral. The chemical equilibrium from a saturated state with respect to hydroxyapatite to an unsaturated state is changed due to the formation of acids in the course of metabolism of dietary fermentable carbohydrates by dental biofilm bacteria. If the local $\mathrm{pH}$ at the tooth-biofilm interface drops lower than the critical $\mathrm{pH} 5.5$, the solution is undersaturated and the mineral will tend to dissolve until the solution becomes saturated, i.e. a new saturation state is re-establish (demineralization). Conversely, if the $\mathrm{pH}$ of the solution is above the critical $\mathrm{pH}$, then the solution is supersaturated with respect to the mineral, and more mineral will tend to precipitate out (remineralization). The presence of fluoride ions inhibits demineralization at the crystal hydroxyapatite surfaces during acid challenge and enhances the remineralization processes forming a layer of fluorapatite-like material on the crystal surfaces. ${ }^{13,14}$ The ability of fluoride to modify the demineralization-remineralization processes depends on the fluoride ions delivery from the used product and their presence in the oral environment at the proper time and concentration. ${ }^{15}$ In vitro studies suggest that even low salivary fluoride levels can reduce demineralization and enhance remineralization. ${ }^{16}$ After fluoride varnish application, salivary fluoride levels represent the fluoride available for caries prevention. Based on in vitro studies, fluoride levels exceeding $0.03 \mathrm{ppm}$ in the surrounding solutions of the dental hard tissues result in caries prevention. ${ }^{17-19}$

The main cariostatic mechanism of fluoride varnish is the formation of calcium fluoride-like globules as well as fluoride uptake into the enamel with fluorapatite formation. The deposited globules act as a fluoride reservoir releasing over time calcium and fluoride ions during acids attack, and providing durable cariostatic effect. ${ }^{13,14}$ Fluoride varnishes could also have some antibacterial influence; however, the obtained data is inconsistent. Some studies have not reported any effect on the levels of Streptococcus mutans in saliva or dental plaque, ${ }^{20}$ but others presented some inhibitory impact under in vivo and in vitro conditions. ${ }^{21,22}$ Studies carried out under in vitro conditions presented rapid fluoride release to the medium from fluoride varnishes within the first hours and slower release thereafter, lasting up to 6 months. ${ }^{3,6-8}$ Our data confirmed the highest fluoride release to artificial saliva during the first $2 \mathrm{~h}$ independently on the medium $\mathrm{pH}$. However, different brand varnishes despite the same concentration of fluoride $(2.26 \%$ as sodium fluoride) can release differing amounts of fluoride ions. Shen and Autio-Gold noticed a lower percentage of fluoride release to artificial saliva from Duraphat in comparison to Duraflor ${ }^{\circledR}$ and CavityShield ${ }^{\circledR}$ varnishes but similar slowdown ions emission within 7 to 213 h. ${ }^{6}$ Milburn et al. examining fluoride release into artificial saliva from Duraphat varnish found that the mean cumulative fluoride release was $1.028 \pm 0.174 \mathrm{ppm}$, the rate of fluoride depletion over the first $4 \mathrm{~h} 0.126 \mathrm{ppm}$, and no detectable fluoride ions emission at three weeks. ${ }^{8}$ In contrast to the data, our results displayed higher $\mathrm{cu}$ mulative fluoride release within the first $2 \mathrm{~h}$. Castillo and Milgrom, ${ }^{7}$ and Jablonowski and Bartoloni ${ }^{3}$ noticed sustained and gradual fluoride release from Duraphat varnish. Lippert observed that fluoride release from some fluoride varnishes varied considerably, and it was dependent on the $\mathrm{pH}$ of the dissolution medium. ${ }^{23}$ Fluoride varnishes CavityShield, Nupro ${ }^{\circledR}$, ProFluorid ${ }^{\circledR}$ and Vanish $^{\circledR}$ showed higher fluoride release to saliva than during the first $5 \mathrm{~min}$ of acid exposure, whereas other varnishes $\left(\right.$ Acclean $^{\circledR}$, Enamel-Pro ${ }^{\circledR}$, MI Varnish, Vella ${ }^{\circledR}$ ) revealed the opposite behavior. Our data also showed that the acidity of artificial saliva was associated with levels of fluoride release. Regression analysis displayed that the acidity of the medium had a greater impact than the immersion time of fluoride varnish in the medium.

However, the fluoride levels measured in the in vitro models have no exact clinical implication. In a clinical setting, a reduction of fluoride levels would be more rapid due to the effects of saliva on fluoride retention, along with the effects of such oral functions as including chewing, swallowing, dietary acidic challenges, teeth brushing, flossing and tongue movement. Additionally, saliva is constantly changing in terms of temperature and $\mathrm{pH}$ due to food consumption. Therefore, due to numerous variables there is not possibility to predict a pattern of fluoride release and retention in saliva on an individual level as we have shown in our study. Hence, fluoride release into artificial saliva is no measure for the efficacy of a fluoride varnish. Twetman et al. assessed fluoride concentration in whole saliva after a single application of 3 different varnishes with various fluoride concentration 6\% (Bifluorid $^{\circledR} 12$ ), 2.26\% (Duraphat) and 0.1\% (Fluor-Protector). ${ }^{9}$ They found a significant elevation of fluoride in saliva $1 \mathrm{~h}$ after application of Bifluorid 12 and Duraphat, which lasted $6 \mathrm{~h}$. Our data displayed a substantial increase of salivary fluoride within the first $2 \mathrm{~h}$ after the varnish application, which decreased with the time; however, after $168 \mathrm{~h}$ it was still higher compared to the baseline. Therefore, at least within 7 days (168 h) a single application of the fluoride varnish increases the fluoride in saliva on the cariostatic level (i.e. over 0.03 ppm).

\section{Conclusions}

Under in vitro conditions, fluoride release from Colgate Duraphat Varnish $50 \mathrm{mg} / \mathrm{mL}$ Dental Suspension was dependent on the acidity of the immersion medium. Under in vivo conditions, fluoride release from the varnish was maintained above the baseline the salivary fluoride levels up to $168 \mathrm{~h}$ (i.e. 7 days). The varnish released the maximum amount of fluoride into the saliva in the first hours after application, and the levels decreased at each period thereafter. 


\section{References}

1. Weyant RJ, Tracy SL, Anselmo TT, et al. Topical fluoride for caries prevention: Executive summary of the updated clinical recommendations and supporting systematic review. Am Dent Assoc. 2013;144:1279-1291.

2. http://www.ivoclarvivadent.com/en/productcategories/removableprosthetics/maintain/fluor-protector-s. Accessed December 14, 2017.

3. Jablonowski BL, Bartoloni JA. Fluoride release from newly marketed fluoride varnishes. Quintessence Int. 2012;43:221-228.

4. Chu CH, Lo ECM. A review of sodium fluoride varnish. Gen Dent. 2006;54:247-253.

5. Marinho VCC, Worthinton HV, Walsh T, Clarkson JE. Fluoride varnishes for preventing dental caries in children and adolescents. Cohrane Database Syst Rev. 2012;7:CD002279.

6. Shen C, Autio-Gold J. Assessing fluoride concentration uniformity and fluoride release from three varnishes. J Am Dent Assoc. 2002;133:176-182.

7. Castillo $\mathrm{JL}$, Milgrom P. Fluoride release from varnishes in two vitro protocols. J Am Dent Assoc. 2004;35:1696-1699.

8. Milburn JL, Henrichs LE, Banfield RL, Stansell MJ, Vandewalle KS Substantive fluoride release from a new fluoride varnish containing CXPTM. Dentistry. 2015;5:350. doi:10.4172/2161-1122.1000350

9. Twetman S, Sköld-Larsson K, Modéer T. Fluoride concentration in whole saliva and separate gland secretions after topical treatment with three different fluoride varnishes. Acta Odontol Scand. 1999;57:263-266.

10. Ritter AV, de L Dias W, Miguez P, Caplan DJ, Swift EJ Jr. Treating cervical dentin hypersensitivity with fluoride varnish: $A$ randomized clinical study. J Am Dent Assoc. 2006;137:1013-1020.

11. American Dental Association Council on Scientific Affair: Professionally applied topical fluoride: Evidence-based clinical recommendations. J Am Dent Assoc. 2006;137:1151-1159.

12. Colgate Duraphat Varnish $50 \mathrm{mg} / \mathrm{mL}$ Dental Suspension: http://www. colgateprofessional.com.ph/products/Colgate-Duraphat-Varnish50mgml-Dental-Suspension/specifics. Accesssed December 14, 2017.

13. Conway-McPherson B. Innovation in enamel therapy: The role of fluoride and ACP. ADA CERP: https://www.dentalacademyofce. com/courses/1452/PDF/Innovatns_Enamel_Therapy.pdf Accessed December 14, 2017.

14. Carey CM. Focus on fluorides: Update on the use of fluoride for the prevention of dental caries. J Evid Based Dent Prac. 2014;(Suppl. 14):95-102.

15. Elwood R, Fejerskov O, Cury JA, Clarkson B. Fluoride in caries control. In: Ferejskov O, Kidd E, eds. Dental caries: The disease and its clinical management. Oxford: Blackwell Publishing; 2008:287-328.

16. Ten Cate JM, Duijsters PP. Influence of fluoride in solution on tooth mineralization. II Microradiographic data. Caries Res. 1989;17:513-519.

17. Featherstone JD. Prevention and reversal of dental caries: Role of low level fluoride. Community Dent Oral Epidemiol. 1999;27:31-40.

18. Leverett DH, Featherstone JD, Proskin HM, et al. Caries risk assessment by a cross-sectional discrimination model. J Dent Res. 1993;72:529-537.

19. Leverett DH, Proskin HM, Featherstone JD, et al. Caries risk assessment by a cross-sectional discrimination model. J Dent Res. 1993;72:538-543.

20. Beltrán-Aguilar ED, Goldstein JW, Lockwood SA. Fluoride varnishes. A review of their clinical use, cariostatic mechanism, efficacy and safety. J Am Dent Assoc. 2000;131:589-596.

21. Pinar Erdem A, Sepet E, Kulekci G, Trosola SC, Guven Y. Effects of two fluoride varnishes and one fluoride/chlorhexidine varnish on Streptococcus mutans and Streptococcus sobrinus biofilm formation in vitro. Int J Med Sci. 2012;9:129-136.

22. Baygin O, Tuzuner T, Kusgoz A, Senel AC, Tanriver M, Arslan I. Antibacterial effects of fluoride varnish compared with chlorhexidine plus fluoride in disabled children. Oral Health Prev Dent. 2014;12:373-382.

23. Lippert F. Fluoride release from fluoride varnishes under acidic conditions. J Clin Pediatr Dent. 2014;39:35-39. 
